\title{
Regional Evaluation of Static Efficiency of China's Publishing Industry: Situation, Problems and Countermeasures
}

\author{
Zhang Linxue ${ }^{1, a}$, Wu Yang ${ }^{2, b^{*}}$ \\ ${ }^{1}$ School of Humanities and Law Northeastern University, Shenyang, Liaoning, China \\ ${ }^{2}$ School of Humanities and Law Northeastern University, Shenyang, Liaoning, China \\ a553477244@qq.com \\ ${ }^{b *}$ wuyang98@126.com
}

\section{ABSTRACT}

Based on the Super-efficiency DEA model, the static efficiency and changing situation of publishing industry in 31 provincial administrative regions in China are measured. It is found that the comprehensive efficiency value and scale efficiency value of publishing industry in China decrease year by year, and the pure technical efficiency value increases year by year and tends to be stable. Finally, from the angle of media regulation, put forward the corresponding development strategy.

Keywords: Publishing Industry Efficiency; Super-efficient DEA Model; Media Regulation;

\section{我国出版业静态效率的区域评价：态势、问题及对策 \\ 张琳雪 $1, \mathrm{a}$ 武阳 $2, \mathrm{~b}$}

\author{
${ }^{1}$ 东北大学文法学院，沈阳，辽宁，中国 \\ 东北大学文法学院，沈阳，辽宁，中国 \\ a553477244@qq.com \\ b*wuyang98@126.com
}

\section{中文摘要}

基于超效率 DEA 模型, 测算我国 31 个省级行政区域出版业的静态效率及其变化态势。研究发现, 我国 出版业综合效率值与规模效率值逐年递减，纯技术效率值逐年上升且趋于稳定。最后从传媒政府规制 的角度，提出相应的发展策略。

关键词：出版业效率；超效率 DEA；传媒规制

\section{1. 模型原理解析与研究设计}

\section{1. 超效率 $D E A$ 模型}

Anderson 和 Petersen 于 1993 年提出超效率 DEA 模型。并改进传统 DEA 模型中无法对多个处于前沿面 的决策单元进一步分析的缺点。公式可表示为:

$$
\left\{\begin{array}{l}
\min \left[\theta-\varepsilon\left(\sum_{i=1}^{m} s_{i}^{-}+\sum_{r=1}^{s} s_{i}^{+}\right)\right] \\
\text {s.t. } \sum_{\substack{j=1 \\
j \neq k}}^{n} X_{i j} \lambda_{j}+s_{i}^{-} \leq \theta X_{0} \\
\sum_{\substack{j=1 \\
j \neq k}}^{n} Y_{j} \lambda_{j}-s_{r}^{+}=Y_{0} \\
\lambda_{j} \geq 0, j=1,2, \cdots, n, s_{r}^{+} \geq 0, s_{r}^{-} \geq 0
\end{array}\right.
$$




\section{2. 我国出版业投入要素指标及数据选取}

本文将 31 个省级区域的出版业视为决策单元。选 取各决策单元制造业资产总额 (其中包含印刷和记录媒 介复制业）与区域内出版业从业人员数作为投入变量, 用于表征出版业的资本要素投入与劳动要素投入。投入 变量的数据均来源于《中国固定资产投资统计年鉴》

《中国第三产业统计年鉴》，数据样本年份为 2015一 2017 年。

\section{3. 我国出版业产出要素指标及数据选取}

选取各决策单元图书出版总印数、期刊出版总印数 于报纸出版总印数作为产出指标, 用于表征出版业的产 出变量。产出变量的数据均来源《中国统计年鉴》, 数 据样本年份为 2015-2017 年。

\section{表 1 出版业投入变量与产出变量指标图}

\begin{tabular}{|c|c|c|}
\hline 指标 & 一级指标 & 二级指标 \\
\hline \multirow{2}{*}{ 投入 } & 人员 & 从业人员数 \\
\cline { 2 - 3 } & 资本 & $\begin{array}{c}\text { 制造业资产 } \\
\text { 总额 }\end{array}$ \\
\hline \multirow{2}{*}{ 产出 } & \multirow{3}{*}{ 总印数 } & 图书 \\
\cline { 3 - 3 } & & 期刊 \\
\cline { 3 - 3 } & & 报纸 \\
\hline
\end{tabular}

\section{2. 我国区域出版业静态效率的实证结果}

利用上述指标对我国出版业 2015-2017 的超效率 DEA 值进行测算。2015-2017 年我国各省级行政区域出 版业综合效率的平均值依次为 $0.82 、 0.79 、 0.72$, 规模 效率的平均值依次为 $1.24 、 0.72 、 0.69$, 纯技术效率的 平均值依次为 $0.74 、 1.33 、 1.31$ 。可以看出, 我国出版 业的综合效率值偏低且呈逐年下降的趋势, 并一直保持 于 1 以下。综合效率值偏低主要由规模效率所致, 规模 效率值逐年递减，且 2015一-2016 下滑最为严重。在综 合效率均值方面, 排名前五的省市依次为: 海南、甘肃、 上海、北京、山西。排名后五的省市依次为: 福建、广 东、重庆、山西、河北。其中河北的综合效率连续 3 年 排名全国最低, 其余省市的规模效率与纯技术效率层次 不齐。表明上述省市的出版业应着力于产业改革与创 新, 改革为上, 着力提高产业效率。

静态效率值反映出我国出版产业规模与技术发展 的总体情况: 我国出版业在媒体融合时期的规模效率呈 递减趋势且效率值均小于 1 , 规模效率也呈递减趋势。 表明出版产业与其余传媒产业, 尤其是新媒体产业的媒 介互动、媒介整合情况不合理, 表现为出版产业的产业 规模致使产业综合效率低下。基于此, 出版产业的媒体 整合水平有待进一步提升, 应着重于不同形态媒介规模 的优质组合, 达到 $1+1>2$ 的效果。纯技术效率呈上升趋
势且 2016-2017 的值大于 1 。表明出版产业与其它形态 的传媒产业互动融合时，自身的管理、技术等水平达到 优质标准。这也反映出我国传媒产业的融合之路中, 管 理、技术等因素更容易把控，短时间内可优化调控。相 比之下, 不同传媒产业的规模、结构的融合更为困难, 需长期调整。

\section{3. 我国出版业静态效率的区域评价}

\section{1. 我国出版业现存问题}

\section{1.1 综合效率}

我国出版业综合效率排名前三的地区为: 华南地 区、东北地区与华北地区, 华中地区最低, 并且极值差 异大。这与柳斌杰《发展高品位高质量高效益出版业》 [1]一文中 “出版社整体情况两极分化” 的观点一致。表 明我国出版业现阶段总体发展不均衡, 不充分、地区差 异大、普遍改进空间较大。我国出版业 TFP 指数排名前 三的地区为西北地区、西南地区与华南地区，华东地区 最低。并且排名前四的地区 TFP 指数均大于 1 , 表明我 国出版业在媒体融合的转折期均着力于改革与探索, 效 率值不断提高且趋于稳定。但总体尚有提升看空间。

\section{1.2 规模效率}

规模效率我国 7 大区域中华中地区的规模效率值全 国最低。如图 2 所示, 华中地区省份的规模效率值整体 偏低, 均有很大改进空间。但其纯技术效率值普遍偏高, 均值排名全国第三。表明华中地区出版业的高效率主要 源于其技术与管理等因素, 出版产业规模有待进一步改 革调整。

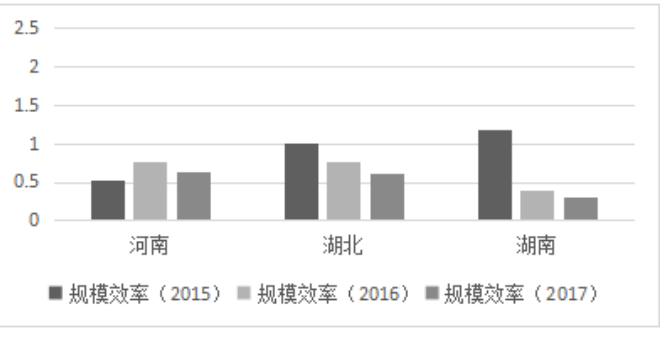

图 2 华中地区 2015-2017 出版业规模效率柱状图

\section{1.3 纯技术效率}

我国 7 大区域中华北地区的纯技术效率值全国最 低。如图 3 所示, 5 省市的纯技术效率差异大且大部分 省市的纯技术效率值偏低。表明华北地区出版业技术和 管理水平导致华北地区综合效率低下; 但其规模效率值 普遍处于较高水平, 均值排名全国第二。表明华北地区 
出版业效率主要源于优质产业规模结构, 但技术与管理 水平有待进一步提高。

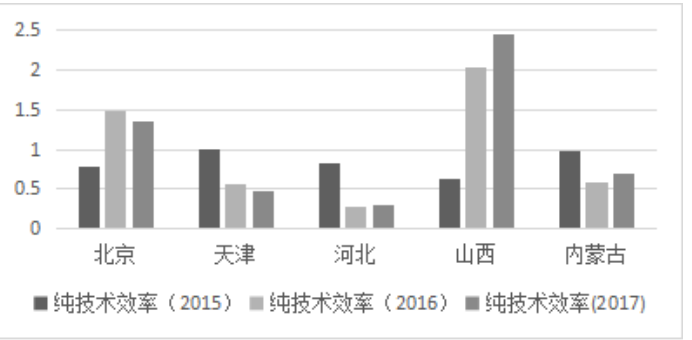

图 3 华北地区 2015一-2017 出版业纯技术效率柱状图

\section{2. 出版产业发展困境的原因阐释}

政府绩效管理是政府各级组织部门之间依据约定 绩效协约而开展的管理活动 ${ }^{[2]}$ 。完整绩效管理过程的实 施是发现问题并解决问题利器。同样, 事先发现问题将 会推动政府管理行为实施的有效性与针对性。我国传媒 产业早已步入产业化进程之中。虽然产出要素不断增 加、产业规模不断扩大, 但经济效益并不理想。从全国 范围来看, 我国出版业的综合效率值不容乐观, 其主要 因为规模效率值偏低, 即主要因为企业规模因素导致效 率低下。究其原因, 主有三点:

\section{2 .1 产品结构}

我国传媒政府规制对于出版产业管制过于严格，表 现为我国出版业资本产出变量主体为教辅材料, 产品结 构失衡。出版产品对于满足人民美好生活需要的作用不 可替代。因此, 出版产品产出结构应满足不同群众对于 文化层次需求的差异化, 在提高出版品位的基础上打造 多形态、多业态、高质量的产品, 以期适应媒介变迁带 来的受众环境。

\subsection{2 产业投入一产出模式}

我国出版业仍属于粗放型要素投入模式, 产品产出 结构尚未与多业态出版结构的产业环境相匹配, 导致出 版产业社会效益与经济效益的失衡, 表现为产业转型期 出口产品的资金投入与核算问题、传统生产模式企业员 工与领军创新型企业员工缺少的矛盾、传统出版的技术 设备与数字技术引进利用的矛盾。

\subsection{3 媒体环境}

产业化发展受到媒介变迁与媒体融合的冲击, 表现 为印刷、电子、数字、互联网、大数据五种业态并存的 出版新结构与传统印刷产业结构的矛盾, 短时间内调整 产业模式对于企业是一项艰巨挑战。对于此, 因着力于 传统出版内容优势与数字出版技术优势的有机组合, 打
造出版业发展新局势。

\section{4. 基于传媒政府规制的我国出版业发展策略}

\section{1. 推进出版业市场化改革与机构转型升 级，优化产业结构与资本投入一产出模式}

在确保正确的政治导向前提下，降低市场准入门 槛，允许民营资本参与到国有新闻出版企业的改革中 来，弥补国有新闻出版企业发展过程中急需的资本。另 外，可以采用中外合资、中方控股的方式吸引国外著名 的出版集团成为战略投资者，提高我国新闻出版企业国 际化水平 $[3]$ 。

\section{2. 推进出版业的媒体融合进程, 促进数字 出版的发展}

媒介技术的发展使得传统传媒产业面临着转型升 级的挑战, 但也促进新型生产模式的实现。传统编辑出 版行业要想生存和发展，必须紧跟传媒发展形势，走多 元化出版之路。切实推进传统出版向数字出版的转型升 级: 整合现有资源, 积极开辟线上出口、学习成功经验, 在摸索中发展、改革为上, 创新发展。

\section{3. 推进传媒政府规制改革与出版企业的供 给侧改革}

出版企业要根据政府规制背景、媒体融合情况、市 场发展环境优化内部资源配制、改善组织机构体制、提 高自身企业竞争力。在读者转移的现实情况下, 加快供 给侧改革, 满足受众的新需求。优越的制度有利于出版 业在市场中具有更大的发展空间，有更大的发展掌控 度，使得出版企业更加开放灵活地制定适合的战略决 策，积极扩大国内外优质文化资产规模，努力开拓国际 市场 ${ }^{[4]}$ 。

\section{4. 全面提高企业自身技术利用率、管理效 率, 充分发挥规模优势}

我国大部分省市的纯技术效率与规模效率都存在 较大改进空间。应重视创新编辑出版的模式，推动定向 化、个性化阅读模式的发展进程。从企业内部体制机制、 企业外部规制环境出发：提高自身现有技术利用率，并 不断引进新技术, 充分利用新媒体, 促进企业技术效率 的提高; 改善管理体制, 促进自身市场化的发展, 并激 发员工活力与创造力，促进企业管理效率的提高; 充分 利用企业规模, 发展多种利润来源与新出版平台, 促进 企业规模效率的提高。 


\section{项目基金}

本文被中央高校基本科研业务专项资金 资助, 项目批准号 (N182410001)。东北大学 大学生创新训练计划自筹项目（201009）。

\section{REFERENCES}

[1] Liu, B.J. (2019) The goal and path of further development of publishing. N. China reading newspaper. 2019-01-30(006).

[2] Cai L.H, Wu X.H, Bao G.X. (2013) Research on the theory and practice of government performance management. J.academic research, 32-40+159.

[3] Luo R. H. (2017) Research on investment and financing of China's press and publication industry. Journal of Beijing Printing Institute,25 (05): 9-10

[4] Liang J, Wang M. (2018) Research on strategies to enhance the international communication power of China's publishing industry. Science and technology and publishing, (05): 129-134 